Article

\title{
Digital Labour in the Platform Economy: The Case of Facebook
}

\author{
Andrea Fumagalli ${ }^{1}$, Stefano Lucarelli ${ }^{2,3}$ (1) , Elena Musolino ${ }^{2, *}$ and Giulia Rocchi ${ }^{4}$ \\ 1 Department of Economics and Management, Università di Pavia, 27100 Pavia, Italy; \\ andrea.fumagalli@unipv.it \\ 2 Department of Management, Economics and Quantitative Methods, Università di Bergamo, \\ 24127 Bergamo, Italy; stefano.lucarelli@unibg.it \\ 3 Centre d'Économie de la Sorbonne at CNRS, Unit of Research 8174, 75013 Paris, France \\ 4 Axe Économie Politique, Université Paris 1 Panthéon-Sorbonne, 75013 Paris, France; \\ giulia.rocchi@univ-paris1.fr \\ * Correspondence: elena.musolino@unibg.it; Tel: +39-338-68-61-583
}

Received: 4 March 2018; Accepted: 23 May 2018; Published: 27 May 2018

\begin{abstract}
The aim of the paper is to analyse the features of the digital labour connected with the so-called platform economy. Many platform-based business models rely on a new composition of capital capable of capturing personal information and transforming it into big data. Starting with the example of the Facebook business model, we explain the valorisation process at the core of platform capitalism, stressing the relevance of digital labour, to clarify the crucial distinction between labour and work. Our analysis differs from Fuchs and Sevignani's thesis about digital work and digital labour and seems consistent with the idea that Facebook extracts a rent from the information produced by the free labour of its users.
\end{abstract}

Keywords: organization of digital labour; platform economy; valorisation process

\section{Introduction}

Notwithstanding the Internet bubble bursting during the late 1990s, the diffusion of information and communication technologies (ICT) continues to mark the 2000s. Particularly in recent years, we have witnessed a significant technological acceleration. Several sectors have been affected. These are industries that have more and more to do with the management of human life (for instance, the Human Genome Project, started in 1990 and concluded in 2003, opened enormous spaces in the possibility of the manipulation of individual life and its procreation [1]). As stressed by Robert Boyer "this sort of regime is an extension of the continued reassessment which has gone on concerning the potential of the information economy" [2]. If the ICT technological paradigm has hit employment levels in the manufacturing industry hard, the new bio-technological wave risks having even greater effects on the traditional and advanced tertiary sectors, which in the last decades have played a compensative role against the loss of jobs in traditional industries.

The development of second generation algorithms [3] is allowing an automation process unprecedented in human history. Applied to machine tools, through computer technologies and nanotechnologies, they are able to transform them into increasingly flexible and ductile instruments and means of production. Second generation algorithms differ from the first generation due to their cumulative self-learning nature, hence configuring a new relationship between human and machine. Actually, after the first stage of implementation and creation, thanks to human behaviour, they are then able to operate in an almost total condition of automation (machine learning). The current technologies however, cannot operate without the acceleration (compared to the recent past) of the degree of 
collection and manipulation of extremely large amount of data in more and more narrow spaces and with ever-increasing high speed. Already in 2011, research by McKinsey's Global Institute examined the state of digital data and recognized the significant value that can potentially be unlocked:

"There are five broad ways in which using big data can create value. First, big data can unlock significant value by making information transparent and usable at much higher frequency. Second, as organizations create and store more transactional data in digital form, they can collect more accurate and detailed performance information on everything from product inventories to sick days, and therefore expose variability and boost performance. Leading companies are using data collection and analysis to conduct controlled experiments to make better management decisions; others are using data for basic low-frequency forecasting to high-frequency now casting to adjust their business levers just in time. Third, big data allows ever-narrower segmentation of customers and therefore much more precisely tailored products or services. Fourth, sophisticated analytics can substantially improve decision-making. Finally, big data can be used to improve the development of the next generation of products and services." [4].

As argued by Martin Kenney and John Zysman, among others, "the algorithmic revolution and cloud computing are the foundations of the platform economy. But computing power is only the beginning of the story. That computing power is converted into economic tools using algorithms operating on the raw material of data." [5].

In the emerging digital platform economy, data as the final output, which is then realized on the global communication and advertising markets, originates a "network value" as the result of a continuous and dynamic process of interaction between human and linguistic labour and digitalized infrastructures (the platforms) [6]. A necessary (although not sufficient) condition for an algorithm to be exploited at maximum power is the existence of a standardization process of cataloguing the necessary data in relation to the predetermined purpose. This is made possible by the manipulation techniques for so-called "big data", especially the big data analytical/mining techniques for structured and unstructured data (commonly called "data extraction"), as well explained in the literature on technology management by Amir Gandomi and Murtaza Haider [7]. Big data represent not only some of the most granular data ever existing generated second-by-second by every device and part of software connected to the web, but also represent an instrument able to change the deep meaning of human activities and particularly human labour.

In Platform Capitalism, Nick Srnicek provides one of the first systemic Marxist interventions into the discourse around data-driven digitalization and the future of work [8]. According to Srnicek, the evolution of internet technologies has fundamentally altered the scenery of capital accumulation and property relations between firms, and legitimates the following question: does the emergence of platform capitalism constitute a new mode of exploitation? Srnicek offers an innovative framework through which to address this question in his conception of data as 'raw material', but his analysis is limited to the effects of lean platforms on the labour market.

From a Marxian perspective, two other problems should be considered: of what does the transformation process of personal information into big data consist? And, moreover, what is the origin of value in the platform economy?

Starting with the example of the Facebook case, we explain the valorisation process at the core of platform capitalism, stressing the relevance of digital labour as a source of economic value for an ever increasing number of data-fuelled corporations.

The main aim of Section 2 is the presentation of the value creation model used by Facebook. Indeed, the American online social media and social networking service company launched by Mark Zuckerberg represents an example of an advertising platform in which value is essentially based on a process of expropriation of the life skills of individuals. In the traditional way, platform capitalism has mainly to do with the satisfaction of some consumer services and the management of the sectors 
related to the logistics management of commodities. The most affected industries concern the tertiary sector, even if some aspects of the manufacturing sectors are involved. This perspective seems common to Nick Srnicek's argument and the McKinsey reports on big data. This analysis of platform capitalism does not consider other relevant features of the economic model, especially the fact that the human activities on Internet platforms are increasingly integrated with the digital elements of communication and language, as we argue in Section 3. It is then necessary to elucidate the crucial distinction between labour and work in order to propose a specific definition of "digital labour", as we do in Section 4 after discussing the concept within the Marxian debate. We particularly refer to the recent contributions by Christian Fuchs and Sebastian Sevignani (2013) [9] and Trebor Scholz (2017) [10]. Section 5 concludes.

\section{The Case of Facebook}

As shown in Figure 1, Facebook is the undisputed global leader in the social network domain.

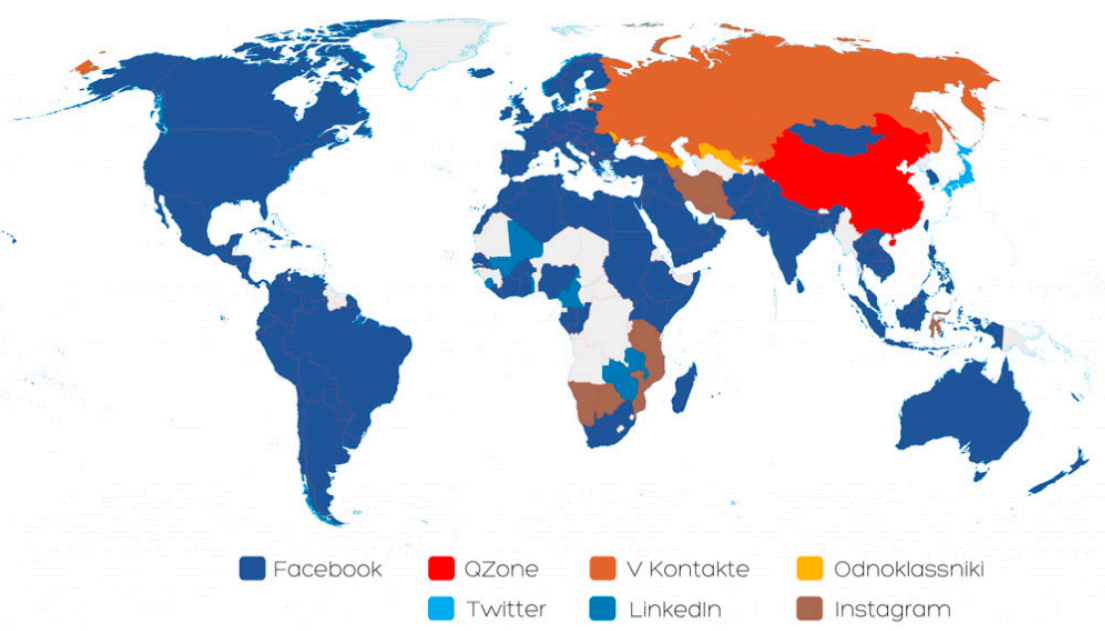

Figure 1. World map of social networks. Source: http:/ /vincos.it/world-map-of-social-networks.

As of the first quarter of 2017, the worldwide number of Facebook monthly active users amounted to 1.94 billion, with an increase of 17\% year-over-year [11]. A monthly active user (MAU) is defined as a registered Facebook user who logged in and visited Facebook through the website or a mobile device, or used the Messenger application at least one time in the last 30 days; this metric, as well as those about the daily active users (DAUs) and the average revenue per user (ARPU), do not include Instagram, WhatsApp, and Oculus users [12].

According to the Facebook Annual Report, revenue was \$27.64 billion in 2016, up 54\% year-over-year, and advertising revenue, accounting for almost the whole cited amount, increasingly originating more from mobile devices than through desktop computers [13], was $\$ 26.89$ billion, with a growth rate even higher than that of revenue. In the specific case of Facebook, mobile advertising revenue represented roughly $83 \%$ of total advertising revenue in 2016 . Where does this value come from?

\subsection{Facebook: The Creation of a Giant}

The story of the world's most popular social network is notorious. The company's roots have to be examined in the academic context. The early version of the site, called "Thefacebook" and founded in February 2004 by Mark Zuckerberg-a student of psychology at Harvard University and passionate about software programming — could be joined only by users who owned a Harvard.edu email address [14,15]. In view of the remarkable success achieved [16]—the site registered 1200 subscriptions within $24 \mathrm{~h}$, covering over half of the undergraduate population one month later-the network rapidly expanded to all American universities, became "Facebook" in August 2005 and 
broadened its horizon beyond educational institutions, becoming accessible to any e-mail address holder aged at least 13 .

Over the course of little more than a decade, Facebook has acquired 65 companies (inclusive of assets and talents) for a total of more than $\$ 23$ billion in expenditure, excluding undisclosed acquisition sums [17].

This big block of acquisitions can be broken up into four main segments, each of which follows a precise marketing strategy tied to the gradual evolution of the company:

1. The first includes all those purchases aimed to improving features of the Facebook website: among these we find FriendFeed (a real-time feed aggregator whose "Like" button and "News Feed" functions have become Facebook's hallmarks since 2009), Octazen Solutions (whose contact importer service was incorporated into "Facebook's Friend Finder" in 2010), and DivvyShot (whose photo-sharing technologies were integrated into "Facebook Photos" in the same year).

2. The second subset encompasses acquisitions needed to enter the smartphone industry: SnapTu (a mobile application platform) and Beluga (an instant group messaging app and web service also) represent the foundations of Facebook Mobile and Facebook Messenger (a messaging app both for mobile and desktop computers, separated from Facebook's platform). In this field, we also find the most expensive company investments: in 2012 Instagram (a photo-sharing social network still working under its own brand although some of its features have been integrated into Facebook) was bought for $\$ 1$ billion, while the acquisition of WhatsApp (a free mobile messaging app) was valued at $\$ 19$ billion.

3. The third segment concerns the implementation of Facebook's advertising revenue model. In 2013 the company absorbed and re-designed the ad-serving and ad-campaign performance measurement platform Atlas Solutions, previously owned by Microsoft. This acquisition permitted to match Atlas' own tracking techniques with Facebook's huge repository of anonymized first-party data, insights from offline purchase data providers and people-based advertising (Facebook has partnered with third party data vendors, that is, the data brokers Axciom, Epilson, Experian, Datalogix, Oracle, and Quantium to reach people on the basis of what they buy and do offline [18]). Instead of the outdated cookies-based model, which has become unreliable since the advent of mobile and the consequent change in users' purchasing behaviour, which shifted to cross-device habits, this investment appeared to some observers [19] as an attempt to build an ad network outside of Facebook, challenging Google's domain in online display advertising. The decision, announced in 2016, to move Atlas from Facebook's ad tech group to its measurement division due to bad quality and fraud issues [20], resulted in the synchronous closure of both Facebook Exchange [21] (a desktop ad-exchange service allowing third party companies to buy advertising spots on the social network) and LiveRail [22] (a video ad-exchange acquired in 2014 for half a billion dollars). This decision mirrored Facebook's intentions to build a closed and centrally controlled "off Facebook" digital advertising ecosystem, a "walled garden" that keeps data sheltered from other parties' access, called the Facebook Audience Network [23]. The latter, working in synergy with Facebook Ads Manager, represents company essential revenue source of the company.

4. The fourth and final segment concerns diversification, namely acquisitions in sectors other than social advertising. Nonetheless, these purchases can be considered still strongly related to its core business. In 2014, Facebook acquired the virtual reality tech company Oculus VR, the fitness/health tracking app company ProtoGeo, and the UK solar-powered drone maker Ascenta. This latter talent acquisition — combined with a team composed of members of the NASA Jet Propulsion Laboratory, NASA Ames Research Centre, and the National Optical Astronomy Observatory - has been functional to the development of a larger project in the framework of a specifically created Research and Development group called Connectivity Lab: Internet.org [24], in partnership with some telecom industry giants. The project is a mobile application with the goal of bringing affordable internet access to that still-prevalent portion of the world that has not 
yet experienced the 'benefits of connectivity,' of using vehicles such as, precisely, high altitude solar powered unmanned aircrafts (that is, drones), lasers and satellites. The platform was rechristened with the less pretentious name of "Free Basics" in September 2015, after digital rights groups from 31 countries signed an open letter [25] to Zuckerberg, saying that Internet.org, by providing access to a tiny and selected set of websites and services rather than to the full Internet, 'violates the principles of net neutrality, threatening freedom of expression, equality of opportunity, security, privacy and innovation'.

\subsection{Facebook's Business Model}

According to an e-Marketer survey [26] addressed to 551 social media marketers around the world, Facebook is the most effective social media advertising platform, producing the highest return on investment (ROI) for almost $96 \%$ of the sample. When we consider that social advertising spending worldwide is forecast to account for $20 \%$ of all internet advertising by 2019 [27] and is predicted to overtake newspaper advertising investments, we can reasonably think that most of this expenditure will end up in the hands of the Menlo Park company. What cannot be contested in any way is that Google and Facebook are not two "duopoly competitors", but rather two independent Internet advertising monopoly platforms that work complementarily in two different fields, respectively search advertising and social media advertising, capturing together more than a half of all the growth in global ad spending [28].

Facebook's business model has become more like Google's since the addition of Facebook Audience Network (FAN) to its advertisement management tool Facebook Ads Manager [29] in 2014. FAN is a mobile-focused network that provides advertisers with new means to extend their campaigns outside the boundaries of Facebook itself, leveraging Facebook's unrivalled trove of personal data, and using the same highly personalized targeting and measurement tools available for regular Facebook ads-other valuable sources of information are the "Like" and "Sign in with Facebook" buttons scattered around the Web.

This change took place through the subsequent steps. FAN was conceived at first as an in-app advertising network that allowed any advertiser to buy ad spaces from any third-party app developer (not only apps created using "Facebook for Developers" [30]). It expanded in 2016 to include, in addition to apps, third-party mobile websites that have opted into the network, further enlarging the likelihood of reaching the right off-Facebook audience, but still restricting it to signed-in Facebook users [31]. In this same year, the company announced that also people without a Facebook account have become targets for Facebook-powered, very informed ads [32]. It is then clear that Facebook's FAN operates in the same way as Google's AdSense.

We will now take a quick look at Facebook's complex, demand-side marketing environment, which leans on the dedicated website [33].

By creating a Business Manager account, an advertiser will be able both to self-administer their Facebook Pages and ad accounts, and to count on ad hoc broker marketing agencies. After setting up account information (such as business name and address, currency, time zone etc.), billing and payment information, and the monthly advertising budget, they will be ready to self-arrange their advertising campaign by using the just-created Facebook Ads Manager account.

Figure 2 shows how a Facebook campaign is structured, consisting of one or more ad sets in turn comprised of one or more ads. 


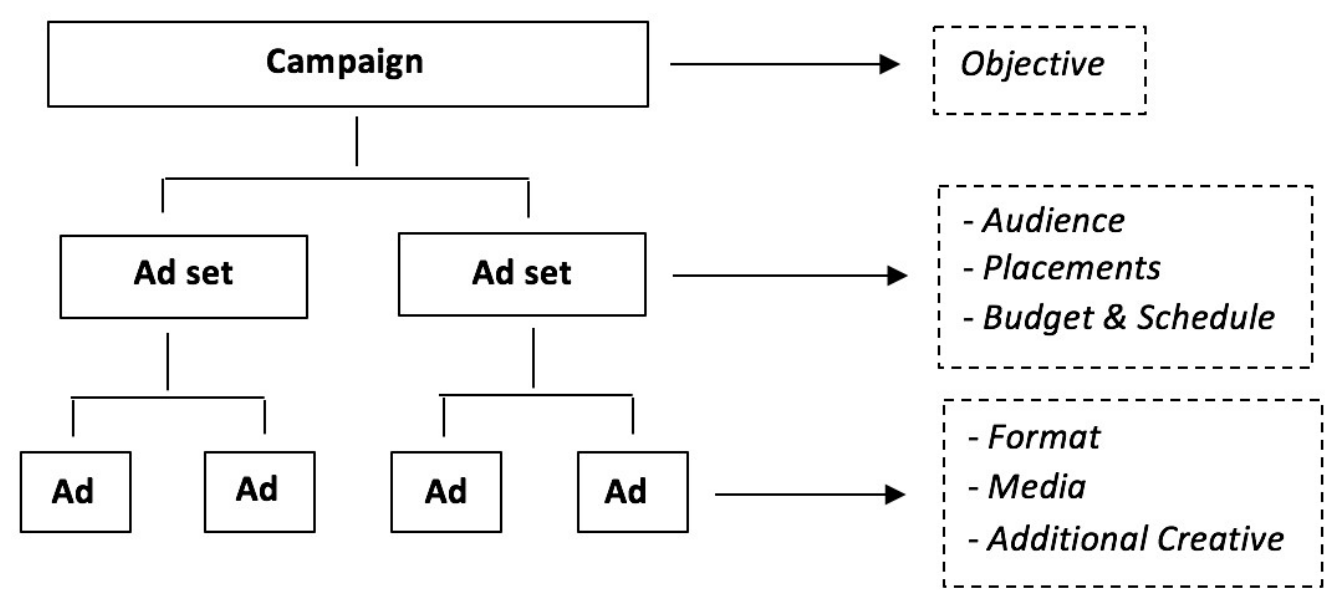

Figure 2. Facebook ad campaign structure.

The campaign's ultimate objective will determine ad formats and bidding options. Facebook offers a wide set of goals grouped into three main categories: awareness, consideration and conversion. One campaign can have multiple ad sets. In this phase a target audience can be defined, on the basis of three primary audience types (saved, custom and lookalike audiences) and taking advantage of location, demographics, interest, behaviour, website traffic, app activity, and engagement-based targeting. Ad placements can either be left to Facebook's automatic choice or manually configured: they will appear on desktop or mobile devices (or on both) and in multiple places, including: Facebook news feed, Facebook right-hand column, Instagram, Messenger, and Facebook's external net, namely FAN. Assigning a budget (be it daily or lifetime, and based on a Cost-Per-Click-CPC, Cost-Per-Mille-CPM, or Cost-Per-Action-CPA bidding strategy) and a schedule (by choosing which weekdays and time slots ads will be displayed) is the third step. The ad delivery takes place in the frame of a worldwide auction that is joined by hundreds of thousands of advertisers. Each time an auction occurs, Facebook will combine three factors (bid amount, relevance score, and estimated action rate) into a total value. The ad with the highest total value will be eligible to appear in the most suitable corners of Facebook's ecosystem. The first factor is the maximum sum the advertiser is willing to pay to win the ad space and it is likely to always be lower than the effectively charged amount. The second factor is Google Quality Score's twin, a score on a scale of 1 to 10 that rates an ad based on how relevant (that is, the level of "attention" the ad receives in terms of likes, shares, comments, clicks, conversions, etc.) it proves to be to the targeted audience. This means that targeting the right audience will lead to a good Click-Through Rate (CTR) on the ad, a ratio that indicates the number of click on an advertisement divided by the number of times the ad is displayed. The CTR in turn will lower the CPC/CPM/CPA, and will increase the relevance score. Finally, the estimated action rate is an appraisal of the likelihood that a user will perform the actions required to achieve the results that the advertiser has bet on. Each ad set can be composed of a bundle of ads, whose format (highly customizable), media channel and additional creatives (to further tailor the ad) should be carefully chosen according to the campaign's objective.

On the supply side we find the above-mentioned Facebook Audience Network (tool) [34], which helps publishers and developers monetize their mobile websites and applications' inventories by hosting Facebook-powered ads that match the interests of their audience, creating a sort of "virtuous circle," where ads that match users' predilections drive better results for advertisers, which means more ad revenue for publishers and developers. Due to Facebook's unequalled knowledge of its clientele's habits, inclinations, tastes, and so on, ads have the potential to be tremendously compelling and their formats vary widely: native ads adapt their appearance to websites and application contents, in order to be perceived as non-intrusive purchasing advice, interstitial ads are full screen ads that pop 
up all of a sudden, while in-stream video ads, that is $15 / 20$ seconds mid-roll videos shown to users while they are watching a video, are among the most profitable FAN ads formats.

Revenue streams arising from clicks (or conversion actions) on ads placed in Facebook News Feed, right-hand column, Instagram and Messenger through Facebook Ads Manager belong to Facebook and Facebook alone. Diversely, Facebook shares a percentage of its advertising profit with those publishers and developers which, by adhering to FAN, house ads within their mobile websites and applications (the latter conceived both through "Facebook for Developers" or by adopting any other app-building platforms).

Figure 3 tries to depict in a simplified way the value creation model of Facebook.

1. Facebook's platform offers a costless vast array of technology features to its subscribed users.

2. Users provide Facebook (who takes note of every single bit) with information of all kinds, from more standard to less intuitive types of data [35].

3. Through Facebook Ads Manager, advertisers purchase advertising slots from Facebook, based on a real-time auction mechanism.

4. Ads are displayed on publishers'/developers' websites/apps who, being registered to FAN (net) through FAN (tool), are paid for hosting Facebook-powered ads.

5. Ads are displayed also on Facebook platform itself (Facebook news feed for desktop and/or mobile, Facebook right-hand column, Instagram, and Messenger).

6. Advertising spaces can be purchased/offered either directly through Facebook Ads Manager/FAN (tool) or indirectly through an advertising agency.

7. Advertiser/publisher/developer expenses/revenues do not depend on the actual purchase of the advertised product or service, but on the number of user clicks on the ads, namely on the mere "attention" that they generate (by chance, mistake or real interest) for ads.

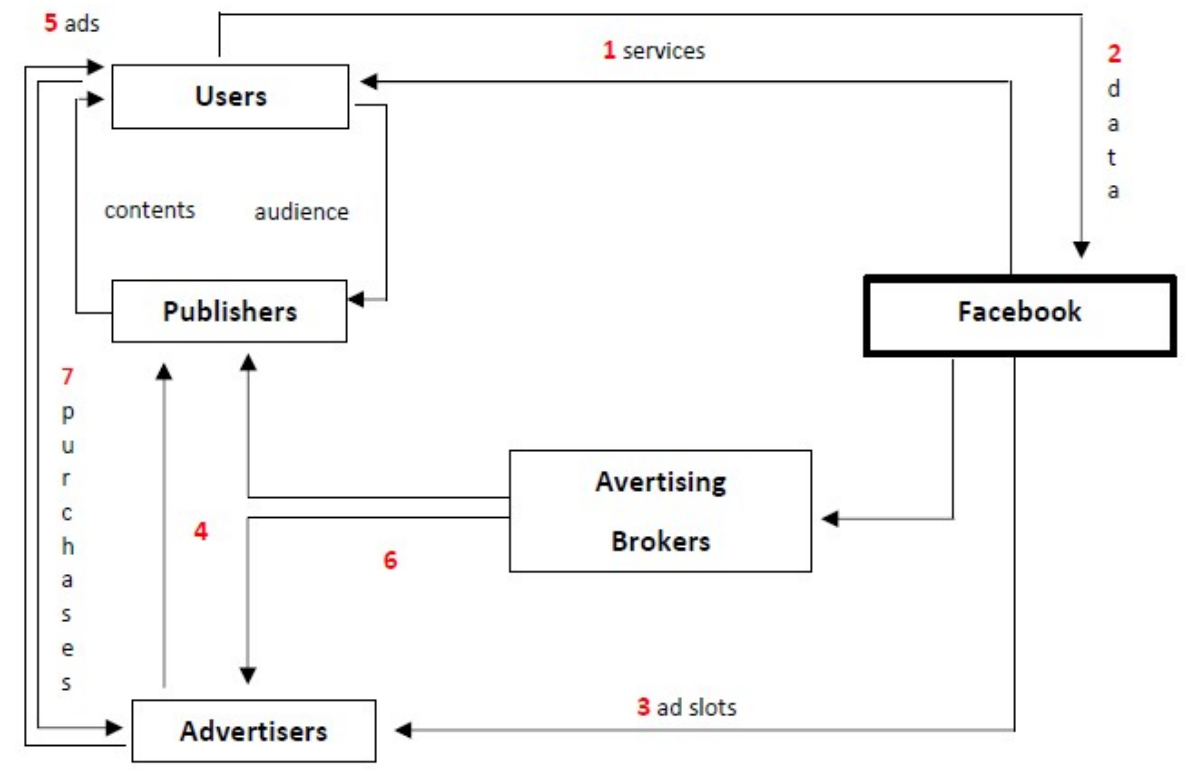

Figure 3. Value creation model: a simplified framework.

Compared to Uber, Deliveroo and Foodora, Facebook represents a different ideal type, in which the labour performance is not immediately perceivable as a field of physical and intellectual efforts. Indeed, the digital labour on Facebook is the above relational activity, or "labour" of social reproduction [36]. Consequently, platform capitalism is a mode of production determining a process of accumulation that is not only founded on the exploitation of knowledge, but also of the entirety of 
the human faculties, from the relational-linguistic to the affective-sensorial. For this reason, Fumagalli and Morini have proposed the use of the term bio-capitalism $[37,38]$.

The production process from personal information to big data is also a transformation of personal emotions (in this sense we may define them as emotional-affective labour) into value by means of a specific digital infrastructure (Facebook Ads Manager).

\section{The Transformation Process and the Sources of Valorisation in the Platform Economy}

The creation of data value (or network value) [6,39], through the processing of digital data and languages inside an algorithm, takes place mainly in some sectors, with different types of platforms.

According to the literature [8,40-42], we can identify six main types of platform. The list would probably increase according to the dynamics of the process of accumulation and valorisation through the digital economy, in terms of production, social life and politics:

- Advertising platforms like Google and Facebook, extracting information from their users to resell their profiles in the form of advertising spaces.

- Cloud platforms such as Amazon Web Services, which create hardware and software for digital-dependent markets and lease them to businesses of all kinds, creating monopolies on knowledge.

- Industrial platforms like General Electric or Siemens, building hardware and software at lower production costs, manufacturing and transforming goods into services (Industry 4.0).

- Product platforms like Spotify, which generates profits by relying on other platforms that transform a commodity like music in a service, and earn through share of subscription paid to subscribers to the aforementioned service.

- Work platforms such as Uber, Airbnb, Deliveroo or Foodora, which organize the workforce through an algorithm and connect customers and businesses by drawing profit through the reduction of labour costs.

- Logistic platforms like Amazon, that govern trade and the displacement of goods.

Platforms collect data in order to be processed. They are a productive input in an immaterial production cycle, whose output (advertising, relationships, induction to consume, ... ) produce an exchange value ("data value"), on the basis of the appropriate algorithmic technology (the same platform).

However, this process is far from being homogeneous and precise. In fact, in the management of logistic clouds [43] (i.e., big data) there is confusion, approximation and heterogeneity, also due to the imperfection of the technologies used, which are continually being improved, also thanks to the involvement of data suppliers and users.

Consider, for example, the translation service offered by Google; the difference to other translation systems regards the use of a larger and very chaotic dataset. This is not a translation word by word, but an analysis of millions of official texts that come from sources such as the United Nations and that provide large amounts of data:

"Despite the confusion of the input, the Google system works better. Its translations are more accurate than those offered by other systems. And it is much, much richer. In mid-2012, its dataset covered over 60 languages. He was even able to accept voice input in 14 languages to make translations more fluid. And since it treats the language simply as a chaotic mass of data to which the calculation of probabilities can be applied, it can even translate between two languages like Hindi and Catalan" [44] (p. 132).

The example of Google translator is paradigmatic of the valorisation process underlying platform capitalism and big data manipulation. On the one hand, the algorithm is able to integrate through a given procedure all the information and suggestion freely provided by the social cooperation (general 
intellect) that the translation service needs; on the other hand, the increasing accuracy of the service is one of the possible reasons for the leadership of Google in the web space [45].

The traditional mechanism is then replaced by more disordered and flexible mechanisms, such as tagging, which is widely used on the Internet. This system allows you to label mainly photos or videos, in order to make the numerous contents available on the network traceable, through tags created by users. The confusion in this case may be due to the incorrect writing of the tags and the way they are organized. All this, however, allows wider access to the various data with a richer universe of labels. Table 1.

The heterogeneity of data and the possible variants of big data can be highlighted in the following

Table 1. Possible variants of big data: Davemport taxonomy.

\begin{tabular}{cccc}
\hline Type of Data & Source of Data & Sector & Function \\
\hline Big volume & Online & Financial Services & Marketing \\
Unstructured & Video & Health & Logistics \\
Continuous flows & Sensors & Manufacturing & Human Resources \\
Multiple Formats & Genomics & Tourism/Transport & Finance \\
\hline \multicolumn{4}{c}{ Source: Davemport, 2014 [46]. }
\end{tabular}

This division, which is as questionable as any taxonomy, highlights a transversal sector that we can define as business intelligence. This is a corporate function that aims to extract value from data in order to perform various production purposes. It refers to:

"The set of business processes to collect data and analyse strategic information, the technology used to implement these processes and the information obtained as a result of these processes" [46] (p. 54).

Therefore, business intelligence is a system of models, methods, processes, people and tools that make it possible to regularly collect and distribute the data generated by a company and through elaborations, analyses and aggregations. The result is knowledge transformed into information usable in a simple, flexible and effective way to provide support for strategic, tactical and operational decisions.

The business intelligence system therefore involves:

- company data collection;

- their cleaning, validation and integration;

- the subsequent data processing, aggregation and analysis; and

- the fundamental use of this amount of information in strategic and enhancement processes.

In this way, it is possible to structure a real life cycle of the valorisation of the big data system, which can be described on the basis of a succession of operations that start with the "capture/appropriation of data", their "organization", "integration", "analysis" and "action".

In the vast majority of cases, especially as regards unstructured data (around $80 \%$ of the total), these data are created as use values, produced and socialized by users/consumers in the performance of daily cooperation and relation activities. It is no coincidence that we speak of capture or rather of more or less forced or voluntary expropriation.

This life cycle describes, in a nutshell, the process of enhancing big data. It is worth dwelling on the two "organizing" and "integrating" operations. These are two operations that only in recent years have reached a certain degree of sophistication, thanks to the technological evolution of second generation algorithms. The organization and integration of data is at the basis of the production of network/data value. It is the productive aspect of exchange value, while "analysis" and "action" represent its commercialization: that is, the monetary realization on the final markets. 
The "capitalism of the platforms" begins to be structured. We refer to the ability of companies to define a new composition of capital capable of managing in an increasingly automated way a process of dividing data according to the commercial use that may derive from it. It is based on the participation, more or less conscious, of individual users, now transformed into prosumers. It is in fact users, by interacting with the platforms, through which they communicate and engage in various forms of relationships, that supply the raw material that is then subsumed in the productive capitalist organization [47]. Machine learning has today become the main tool for the capacity of capital to subsume and capture social cooperation, by deeply transforming the traditional capitalist mode of production. For this reason, some scholars proposed to use the expression "communism of capital" [48,49]. The term "communism of capital" was originally proposed by Paolo Virno to characterize the post-Fordist period in which capital reorganized itself, mobilizing "for its own benefit precisely those material and cultural conditions which would guarantee a calm version of realism for the potential communist" [50] (p. 110).

Algorithms are the basis of machine learning. By algorithm we mean a calculation procedure, a method for solving a problem or a sequence of instructions that tells a computer what to do.

To understand the power of machine learning, we can resort to an analogy reported by Pedro Domingos, in which this type of technology is compared to agriculture: the learning algorithms are the seeds, the data are the soil and the programs learned are the adult plants [3]. The machine learning expert is the farmer who plants the seeds, and irrigates and fertilizes the soil without further interfering. Thanks to this metaphor two aspects emerge:

1. The first is related to the large amount of data, because the more we have, the more we can learn. The spread of machine learning is closely linked to the appearance of big data.

2. The second aspect shows instead how a mountain of available data can reduce the complexity that characterizes these processes. With machine learning, the process undergoes a strong acceleration. "The Industrial Revolution has automated manual labour, and the Information Revolution has done the same with the intellectual. Machine learning, on the other hand, automates automation itself: if it were not there, programmers would become bottlenecks that curb progress" [3] (p. 14).

Algorithms help us to navigate the vastness of data on the web, but above all they are able to influence our decisions and cultural context. The ones that perform this function are the algorithms of social networking platforms; every time we use them, we leave information that is recorded, processed and used by other users. It is a collection of individual information subsequently destined to the community. When the algorithms suggest what we (may) like and help us in our relationships, they begin to shape our identity and influence our choices. In the information society the main problem lies in the quantity or, better, in the unlimited choice that big data creates: among the multiplicity of products to choose or opportunities to be seized, which one might be the most suitable for us? Algorithms and machine learning offer a solution. In companies, the operations to be carried out increase over time, just as the number of customers can increase significantly. As a consequence, machine learning becomes fundamental:

"Amazon cannot adequately encode the tastes of all its customers in a program, and Facebook is not able to write a program that chooses the best updates to show to each of its users. Walmart, the distribution giant, sells millions of products and must make billions of decisions a day: if its programmers tried to write a dedicated program, they would never finish. The solution adopted by such companies, instead, is to unleash the learning algorithms on the mountains of data that have accumulated and let them guess what customers want" [3] (p. 17).

Algorithms are not perfect but, by providing their results, they influence the users and their decisions. They are the intermediaries between data and consumers and concentrate the power and control as modern assembly lines. 


\section{Digital Labour or Digital Work?}

The Facebook case we presented in the previous section is a good example of an advertising platform. At the same time, the Facebook value-creation model seems to transform the very nature of business. Moreover, the extraordinary volume of big data represents the results of a complex process of production that suggests that we rethink the crucial distinction between labour and work. Indeed, in the last decade businessmen, social scientists and policy makers have introduced the notion of "digital labour" to intend two different innovative situations in the labour market:

1. Digital labour has been used to describe the labour-force of independent contractors who work on their own account and at their own risk for low wages and without social security, as in the case of many platform-based business models like Uber, Foodora or other work and logistic platforms.

2. Digital labour means also the human activity used by other platform-based business models like Facebook or Google that rely on a new composition of capital capable of capturing personal information and transforming it into big data.

In the first sense, the terms refer to a classical form of waged labour characterized by a deep reduction of workers' rights by means of digital technologies. Consequently, we suggest abandoning the notion of "digital labour" and use the notion of "digital work".

In the second sense, the terms imply innovative sources of valorisation. "Digital labour" introduces new forms of exploitation that go beyond the classical waged relationship.

The disappearance of a clear distinction between life time and labour time is one of the distinctive traits of digital labour and explains why this concept has become a crucial foundation of discussions within the realm of the political economy of the Internet [51,52], labour sociology [53-56] Marxian studies and especially the hypothesis of (bio)cognitive capitalism [57-61].

As Christian Fuchs and Sebastian Sevignani write:

"The basic argument in this debate is that the dominant capital accumulation model of contemporary corporate Internet platforms is based on the exploitation of users' unpaid labour, who engage in the creation of content and the use of blogs, social networking sites, wikis, microblogs, content sharing sites for fun and in these activities create value that is at the heart of profit generation" [9] (p. 237).

Regarding digital labour and digital work, our view differs from Fuchs and Sevignani's analysis. Combining Marx's thoughts with Hegel's philosophy of work and labour, those scholars argue that creativity, self-regulation and the social dimension of work are valued and recognized especially in digital society. They recognize that digital labour is exploited, although exploitation does not tend to be properly and consciously felt because digital labour is conceived as play labour. Consequently, it hides the reality of exploitation behind the fun of connecting with and meeting other users. However, Fuchs and Sevignani tend to take too lightly the relevance of the new composition of capital capable of capturing personal information and transforming it into big data. Instead, they affirm that Facebook is a realm of cognitive, communicative and co-operative activities that are work. In order to justify their thesis, Fuchs and Sevignani write that "according to Marx, in order to speak of work, there must be an interaction of labour power with objects and instruments of work so that use-values are created as products" (ivi, p. 255).

However, it is hard to see in our context how Facebook users may be considered as exploited workers. Facebook does not organise the social cooperation of users directly, and do not conceive them as part of a working class, i.e., people who have to work to get money. As we have argued in the previous paragraphs, cooperation is organised beyond a workplace and is increasingly independent of Facebook's direct control. The company launched by Mark Zuckerberg captures personal information. As clearly shown by Tiziana Terranova, Facebook may be conceived as a product of "free labour" [62] in which "prosumers" produce and use the social networking site to communicate and develop their 
proper social networks, and at the same time contribute to the creation of Facebook's main product: user data and audience attention.

The big data industry creates value based on a production process for which the raw material is the life of individuals. This "raw material" is largely provided free of remuneration.

The "secret" of accumulation lies in the transformation of the personal information into exchange value. In other words, the transformation of concrete labour, which is the basis of daily life activities that generate data via social relationships and information needs, into abstract labour.

According to Marx [63] (Volume 1, Section 1.2), concrete labour, qualitatively defined, is aimed at producing use value; abstract labour, on the other hand, is the pure manifestation of human labour-power (Arbeitsvermögen) [64] (pp. 81-125.), which is independent of the qualitative aspects and the specific determinations referring to the usefulness of the individual works and whose quantity determines the created value. In the digital industry, abstract labour is the organization and integration of data.

Of what does the transformation process of personal information into big data consist?

In the first phase a process of original accumulation is carried out as an extension of the productive base to incorporate lifetime, which however is not salaried or remunerated; in most cases it is non-subjectivized, passive participation.

In the second phase, the use of an organized (and salaried) workforce takes over, which proceeds to the processing activity. Here the model of labour organization that is implemented by the algorithm becomes crucial.

In other words, we can say that digital production and platform capitalism show the "dual character of capitalism" [63] (Volume 1, Section 1.2).

According to Marx, when concrete labour is dominant, we are faced with a "labour process" that is able to satisfy human needs and human dreams. This labour is defined by Marx as "necessary" and it is the natural intrinsic operation of human life.

Conversely, when abstract labour is dominant, as happens in the capitalist system of production, the labour process originates a valorisation process and the necessary labour becomes surplus labour.

Digital activity normally starts as concrete labour and becomes abstract labour. This is the role played by platform capitalism.

The capitalist system of production is marked by a continuous evolution of the organization of labour. In the moment when the waged labour is reduced, idleness and leisure are put to value. However, far from favouring the transformation of labour into opus and/or into otium, the opposite happens. It is increasingly the cognitive, artistic and human abilities that are commoditized, salaried and hierarchized. Far from entering the "end of work" era, we are in the presence of an "endless work" age.

How do you measure life time when it becomes productive? As long as the labour performance was directly related to the material dimension, it was measured in terms of the productivity rate, estimated either in terms of time units (how many hours are required to produce a certain amount of output?) or in terms of quantities obtained (how many units of output are produced in a given time interval?). In his last book, Trebor Scholz comes to the same problems:

"Our online identity, so eagerly performed, has a curious afterlife in faraway data centers where subjectivities and data are turned into monetary value. Without being recognized as labour, our location, expressions, and time spent on the network can be turned into economic value. The tracking and monetization of users is frequently justified with the significant operating costs of platform operators. It is unclear, however, what exactly is recorded, how its value is measured, to whom it is sold, and for what purpose." [10] (p. 69).

By considering the Facebook value-creation model, we may propose a paradigmatic example; value is essentially based on a process of expropriation of the life skills of individuals (or from what we can define, in a very broad sense, general intellect [65] and social reproduction [35]) for purposes 
of private accumulation. The process of creating value is no longer limited to the single working day, but extends to incorporate the whole of human existence, that is, the lifetime that is necessary to generate, again, physical strength, but also affections, relationships, social relations and imaginaries, and therefore social knowledge. Platform capitalism proposes to provide a measure by imposing business logics on the whole of human life through different infrastructures.

Our analysis seems consistent with the so called neo-workerist approach. It may be summarized in the following way:

“The process, described as the 'becoming-rent of profit' (Marazzi, 2010 [66]; Vercellone, 2010 [67]) here becomes apparent: Facebook does not reap a profit merely from organizing the paid labour of its relatively few employees (as labour process theory would suggest), but extracts a rent from the commons produced by the free labour of its users" [68] (p. 2).

\section{Preliminary Conclusions}

The value creation model used by Facebook (Section 2.2) is a typical example of platform capitalism, which can be seen as a specific form of capitalism whereby the central stake of value extraction and accumulation leads to ever greater control and privatization of the collective production of knowledge [69]. The diffusion of digitalized processes is leading contemporary capitalism towards new frontiers. As we have argued above (Section 4), human activities on Internet platforms are increasingly integrated with the digital elements of communication and language; the result leads to a new form of relationship between concrete labour and abstract labour, using Marxian terminology (Section 3). We propose therefore to define "digital labour" as the set of human activities realized outside of working hours, captured by platform-based business models and transformed into value in the form of big data.

Future research should deepen the anthropological evolution that is affecting both the notions of labour and leisure; for instance, the whole social media economy of "likes" is designed based on emotions (the emotional contagion experiment conducted by Facebook is an example of how far these attempts are able to affect our lives [70]).

Platform capitalism (and particularly the Facebook model) represents the frontier of tomorrow. The new technological paradigm based on digital labour can deeply change our way of understanding social, economic and political relations. Here the problem of anthropological sustainability is placed.

Author Contributions: All the authors contributed substantially to the entire work reported. They read and approved the final manuscript. A.F. conceived the theoretical framework and wrote Sections 1, 3 and 4. S.L. particularly developed the critique of Fuchs and Sevignani's thesis and wrote Sections 1, 4 and 5. G.R. performed the analysis of the Facebook business model and wrote Section 2. E.M. contributed to the literature review, editing of manuscript and focussing the difference between digital labour and digital work presented in Section 4.

Funding: This research received no external funding.

Acknowledgments: The authors would like to thank the three anonymous referees for their very useful suggestions. Thank you also to Effimera.org that represents a precious collective experience of critical thought for discussing the new tendencies of contemporary capitalism, particularly to Cristina Morini. Part of the analysis was discussed with the members of CES-CNRS Laboratory UMR-8174 and with the members of NEXA-Politecnico di Torino in the context of DECODE project (funded by European Union's Horizon 2020 Programme under grant agreement number 732546). For this reason, the authors would especially thank Carlo Vercellone, Jean-Marie Monnier and Marco Ciurcina.

Conflicts of Interest: The authors declare no conflict of interest. The founding sponsors had no role in the design of the study; in the collection, analyses, or interpretation of material of research; in the writing of the manuscript, and in the decision to publish the results.

\section{References}

1. All about the Human Genome Project (HGP). Available online: https:/ / www.genome.gov/10001772/allabout-the--human-genome-project-hgp/ (accessed on 1 March 2018).

2. Boyer, R. The Future of Economic Growth; Eward Elgar: Cheltenham, UK, 2004; p. 136. 
3. Domingos, P. The Master Algorithm: How the Quest for the Ultimate Learning Machine Will Remake Our World; Basic Books: New York, NY, USA, 2015.

4. McKynsey Global Institute, Big Data: The Next Frontier for Innovation, Competition and Productivity. May 2011. Available online: https://www.mckinsey.com/business-functions/digital-mckinsey/ourinsights / big-data-the-next-frontier-for-innovation (accessed on 16 May 2018).

5. Kenney, M.; Zysman, J. The Rise of the Platform Economy. Issues Sci. Technol. 2016, 32, 61. Available online: http:/ / issues.org/32-3/the-rise-of-the-platform-economy/ (accessed on 16 May 2018).

6. Fumagalli, A. Per una teoria del valore-rete: Big data e processi di sussunzione. In Datacrazia. Società, Cultura e Conflitti al Tempo dei Big Data; Gambetta, D., Ed.; D Editore: Roma, Italy, 2018.

7. Gandomi, A.; Haider, M. Beyond the hype: Big data concepts, methods, and analytics. Int. J. Inf. Manag. 2015, 35, 137-144. [CrossRef]

8. Srnicek, N. Platform Capitalism; Polity Press: Cambridge, UK, 2017.

9. Fuchs, C.; Sevignani, S. What is Digital Labour? What is Digital Work? What's their Difference? And why do these Questions Matter for Understanding Social Media? tripleC 2013, 11, 237-293. [CrossRef]

10. Scholz, T. Uberworked and Underpaid. How Workers are Disrupting the Digital Economy; Polity Press: Cambridge, UK, 2017.

11. Statista. Available online: https://www.statista.com/statistics/264810/number-of-monthly-activefacebook-users-worldwide/ (accessed on 1 March 2018).

12. Facebook Annual Report (2016). Available online: http://www.annualreports.com/Company / facebook (accessed on 1 March 2018).

13. Statcounter, GlobalStats. Available online: http://gs.statcounter.com/platform-market-share/desktopmobile-tablet/worldwide (accessed on 1 March 2018).

14. Boyd, D.; Ellison, N.B. Social network sites: Definition, history, and scholarship. J. Comput. Med. Commun. 2008, 13, 210-230. [CrossRef]

15. Gebika, A.; Heinemann, A. Social Media \& Competition Law. World Compet. 2014, 37, 149-172.

16. Phillips, S. A Brief History of Facebook. The Guardian, 25 July 2017. Available online: https://www. theguardian.com/technology/2007/jul/25/media.newmedia (accessed on 1 March 2018).

17. Techwyse. Available online: https://www.techwyse.com/blog/infographics/65-facebook-acquisitions-thecomplete-list-infographic/ (accessed on 1 March 2018).

18. Facebook Partner Categories. Available online: https://www.facebook.com/business/a/facebook-partnercategories (accessed on 1 March 2018).

19. Marshall, J. Facebook Extends Reach with New Advertising Platform. The Wall Street Journal, 22 September 2014. Available online: https://www.wsj.com/articles/facebook-extends-reach-withad-platform-1411428726/ (accessed on 1 March 2018).

20. Atlassolutions. Available online: https://atlassolutions.com/2016/03/07/value-with-atlas / (accessed on 1 March 2018).

21. Meola, A. Facebook Is Shutting down Facebook Exchange. Business Insider, 26 May 2016. Available online: http:/ / www.businessinsider.com/facebook-is-shutting-down-acebookexchange-2016-5?IR=T (accessed on 1 March 2018).

22. Shields, M. Facebook Plans to Shut Down Video Ad Exchange Product LiveRail. The Wall Street Journal, 26 May 2016. Available online: https:/ / www.wsj.com/articles/facebook-plans-to-shut-downvideo-adexchange-product-liverail-1464303877 (accessed on 1 March 2018).

23. Peterson, T. How Facebook Turned an End-to-End Ad Tech Strategy on Its Head. Marketing Land, 17 June 2016. Available online: https://marketingland.com/facebook-turned-end-end-ad-tech-strategy-head-181395 (accessed on 1 March 2018).

24. Infointernet. Available online: https:/ / info.internet.org/en/ (accessed on 1 March 2018).

25. Open Letter to Mark Zuckerberg Regarding Internet.org, Net Neutrality, Privacy, and Security. 2015. Available online: https://www.facebook.com/notes/access-now / open-letter-to-mark-zuckerbergregarding-internetorg-net-neutrality-privacy-and-/935857379791271/ (accessed on 1 March 2018).

26. Emarketer. Available online: https://www.emarketer.com/Article/Social-Media-Marketers-FacebookProduces-Best-ROI/1013918 (accessed on 1 March 2018).

27. Fortune. Available online: http:/ / fortune.com/company/pgpef/ (accessed on 1 March 2018). 
28. Zenithmedia. Available online: https://www.zenithmedia.com/google-facebook-now-control-20-globaladspend/ (accessed on 1 March 2018).

29. Business Facebook. Available online: https://business.facebook.com/ (accessed on 1 March 2018).

30. Facebook for Developers. Available online: https://developers.facebook.com/?locale=en_UK (accessed on 1 March 2018).

31. Chaykowski, K. Facebook Extends Its Ad Network To Mobile Websites. Forbes, 20 January 2016. Available online: https:/ / www.forbes.com/sites/kathleenchaykowski/2016/01/26/facebook-extends-its-ad-networkto-the-mobile-web/\#1fe829b7132e (accessed on 1 March 2018).

32. Slefo, G. Facebook to Serve Ads to Non-Users through Its Audience Network. Advertising Age, 27 May 2016. Available online: http:/ / adage.com/article/digital/facebook-serve-ads-users-audience-network/304195/ (accessed on 1 March 2018).

33. Facebook Business. Available online: https://en-gb.facebook.com/business (accessed on 1 March 2018).

34. Audience Network by Facebook. Available online: https://www.facebook.com/audiencenetwork (accessed on 1 March 2018).

35. Dewey, C. 98 Personal Data Points that Facebook Uses to Target Ads to You. The Washington Post, 19 August 2016. Available online: https:/ /www.washingtonpost.com/news/theintersect/wp/2016/08/19/ 98-personal-data-points-that-facebook-uses-to-target-ads-toyou/?utm_term=.038a29370111 (accessed on 1 March 2018).

36. Morini, C. Social Reproduction as a Paradigm of the Common. Reproduction Antagonism, Production Crisis. In Post-Crisis Perspectives; Augustin, O., Ydesen, C., Eds.; Peter Lang: Frankfurt, Germany; New York, NY, USA, 2013; pp. 83-98.

37. Fumagalli, A.; Morini, C. Life put to work: Towards a life theory of value. Ephemer. Theory Polit. Organ. 2010, 10, 234-252.

38. Codeluppi, V. Il Biocapitalismo. Verso lo Sfruttamento Integrale di Corpi, Cervelli ed Emozioni; Bollati Boringhieri: Torino, Italy, 2008.

39. Pasquinelli, M. Italian Operaismo and the Information Machine. Theory Cult. Soc. 2015, 32, 49-68. [CrossRef]

40. Smith, A. Gig Work, Online Selling and Home Sharing. Pew Research Center, 17 November 2016. Available online: http:/ / www.pewinternet.org/2016/11/17/gig-work-online-selling-and-home-sharing/ (accessed on 1 March 2018).

41. Vecchi, B. Il Capitalismo delle Piattaforme; Manifestolibri: Roma, Italy, 2017.

42. Tarleton, G. The Platform Metaphor, Revisited. Alexander Von Humboldt Institut für Internet und Gesellschaft. 24 August 2017. Available online: http:/ / culturedigitally.org/2017/08/platform-metaphor / (accessed on 1 March 2018).

43. Mosco, V. To the Cloud: Big Data in a Turbulent World; Paradigm Publishers: Boulder, CO, USA, 2014.

44. Mayer Schoenberger, V.; Cukier, K. Big Data: A Revolution that Will Transform How We Live, Work, and Think; Eamon Dolan Book: Boston, NY, USA, 2013.

45. Carr, N. The Big Switch: Rewiring the World, from Edison to Google; W.W. Norton \& Company: New York, NY, USA, 2008.

46. Davemport, T.H. Big Data at Work: Dispelling the Myths, Uncovering the Opportunities; Harward Business Review Press: Boston, NY, USA, 2014.

47. Booth, A. Marx's Capital: Chapter 15-The Machine. Available online: https://www.socialist.net/marx-scapital-chapters-15-the-machine.htm (accessed on 20 April 2018).

48. Beyerungen, A.; Murtola, A.M.; Schwartz, G. The communism of capital. Ephemer. Theory Polit. Organ. 2013, 13, 483-495.

49. Marazzi, C. Il Comunismo del Capitale. Biocapitalismo, Finanziarizzazione Dell'Economia e Appropriazioni del Comune; Ombre Corte: Verona, Italy, 2010.

50. Virno, P. A Grammar of the Multitude: For an Analysis of Contemporary Forms of Life; Semiotext(e): New York, NY, USA, 2004.

51. Burston, J.; Dyer-Witheford, N.; Hearn, A. Digital Labour: Workers, Authors, Citizens. Ephemer. Theory Polit. Organ. 2010, 10, 214-221.

52. Scholz, T. (Ed.) Digital Labour. The Internet as Playground and Factory; Routledge: New York, NY, USA, 2012.

53. Huws, U. Labor in the Global Digital Economy: The Cybertariat Comes of Age; Monthly Review Press: New York, NY, USA, 2104. 
54. Huws, U. New forms of platform employment. In The Digital Economy and the Single Market; Wobbe, W., Bova, E., Dragomirescu-Gaina, C., Eds.; Foundation for European Progressive Studies: Brussels, Belgium, 2014; pp. 65-82.

55. Cardon, D.; Casilli, A. Qu'est-ce que le Digital Labor? INAGLOBAL, 7 September 2015. Available online: https:/ / www.inaglobal.fr/numerique/article/quest-ce-que-le-digital-labor-8475\#sommaire (accessed on 1 March 2018).

56. Arvidsson, A.; Colleoni, E. Value in Informational Capitalism on the Internet. Inf. Soc. 2012, 28, 135-150. [CrossRef]

57. Fumagalli, A. Bioeconomia e Capitalismo Cognitivo. Verso un Nuovo Paradigma di Accumulazione; Carocci: Roma, Italy, 2007.

58. Fumagalli, A. Twenty Theses on Contemporary Capitalism (Cognitive Biocapitalism). Angelaki 2011, 6, 7-17. [CrossRef]

59. Fumagalli, A.; Lucarelli, S. Valorization and financialization in cognitive biocapitalism. Investig. Manag. Financ. Innov. 2011, 8, 88-103.

60. Moulier-Boutang, Y. Le Capitalisme Cognitif: La Nouvelle Grande Transformation; Editions Amsterdam: Paris, France, 2008; (English Translation. Cognitive Capitalism; Translated by Emery, E.; Polity Press: New York, NY, USA, 2011).

61. Vercellone, C. (Ed.) Capitalismo cognitivo. Conoscenza e finanza nell'epoca postfordista; Manifestolibri: Roma, Italia, 2006.

62. Terranova, T. Network Culture: Politics for the Information Age; Pluto Press: London, UK, 2004.

63. Marx, K. Capital; Penguin Book: London, UK, 2004; Volume 1.

64. Ciccarelli, R. Forza Lavoro; DeriveApprodi: Roma, Italy, 2018.

65. Vercellone, C. From Formal Subsumption to General Intellect: Elements for a Marxist Reading of the Thesis of Cognitive Capitalism. Hist. Mater. 2007, 15, 13-36. [CrossRef]

66. Marazzi, C. The Violence of Capital; Semiotext(e): New York, NY, USA, 2010.

67. Vercellone, C. The Crisis of the Law of Value and the Becoming-Rent of Profit. In Crisis in the Global Economy: Financial Markets, Social Struggles and New Political Scenarios; Fumagalli, A., Mezzadra, S., Eds.; Semiotext(e): New York, NY, USA, 2010; pp. 85-118.

68. Böhm, S.; Land, C.; Beverungen, A. The Value of Marx: Free Labour, Rent and 'Primitive' Accumulation in Facebook. Working Paper Series. University of Essex. May 2012. Available online: https://www. researchgate.net/publication/239735772 (accessed on 17 May 2018).

69. Vercellone, C.; Monnier, J.-M.; Lucarelli, S.; Griziotti, G. Theoretical Framework on Future Knwoledge-Based Economy. D3.1 of D-Cent European Project. 2014. Available online: https:/ / dcentproject.eu/wp-content/ uploads/2014/04/D3.1-final_new.pdf (accessed on 1 March 2018).

70. Sampson, T. Various joyful encounters with the dystopias of affective capitalism. Ephemer. Theory Polit. Organ. 2016, 16, 51-74.

(C) 2018 by the authors. Licensee MDPI, Basel, Switzerland. This article is an open access article distributed under the terms and conditions of the Creative Commons Attribution (CC BY) license (http:/ / creativecommons.org/licenses/by/4.0/). 